Original Article

\title{
Surgical Outcome of Adolescents and Young Children with Tethered Cord Syndrome: A Retrospective Analysis
}

\author{
Ayaz Ahmad', Muhammad Ali Noman', Muhammad Mukhtar², Imran Khan' \\ Muhammad Mushtaq ${ }^{1}$, Shahid Ayub' \\ ${ }^{1}$ Department of Neurosurgery, Hayatabad Medical Complex ${ }^{2}$ North West General Hospital \& Research \\ Hospital Peshawar - Pakistan
}

\begin{abstract}
Objective: In Spinal dysraphism, neural tube defect is one of the leading causes of congenital central nervous system disorders and contributes to a high proportion of disability and mortality. This study aimed to evaluate the outcome of the detethering of tethered cord syndrome.

Materials \& Methods: The study was conducted at the Neurosurgery Department of Hayatabad Medical Complex Peshawar. A total of 110 patients were included in our study. Clinical examination was recorded for back swelling, dermal stigmata, scars, lower limb neurological function, sensory deficits, reflexes. Also, look for any deformities like kyphoscoliosis or limb deformities and the presence/absence of neuropathic ulcers. Imaging studies were recorded for diagnosis, the level of spinal tethering, presence/absence of syrinx, and spine deformities. During the surgical operation, the diagnosis of the lesion was confirmed and the interventional procedure was recorded.
\end{abstract}

Results: One hundred ten patients were admitted during the study period with 57 (52.2\%) females and 53 $(47.8 \%)$ males with a mean age of 9.3 years $(S D \pm 4.3)$. Most patients had presented with pain in lower limbs (60.9\%) and backache was (34.8\%). The most common operative complication was CSF leak in 29 patients (26.1\%) while wound infection occurred in 14 (13\%) cases.

Conclusion: Tethered cord syndrome due to occult spinal dysraphism is a rare disease with significant neurologic consequences for the younger generation. Early clinical diagnosis and good surgical treatment could prevent the development of these complications.

Keywords: Spinal Dysraphism, Spina bifida Occulta, Tethered Cord Syndrome.

Corresponding Author: Ayaz Ahmad

Department of Neurosurgery

Hayatabad Medical Complex

Peshawar - Pakistan

Email: ayaz.neurosurgeon@gmail.com

Date of Submission: 10-08-2021

Date of Revision: 09-09-2021

Date of Acceptance: 20-09-2021

Date of Online Publishing: 30-09-2021

Date of Print: 30-09-2021
DOI: $10.36552 /$ pjns.v25i3.591

\section{INTRODUCTION}

The tethered spinal cord was described as characterized by low lying conus and thickening of the filum terminale. This condition was first described by Hoffman in a landmark paper which described the related characteristics of the 
disease and its outcome to surgical release of the tethering. ${ }^{1}$ Occult spinal dysraphism is a wellknown form of neural tube defects with a relatively rare occurrence and late clinical presentation. It was described by Virchow in 1875 with a recorded first instance of surgical correction performed by Jones in $1891 .^{2}$ Similarly tethered cord syndrome was described as lower spinal cord dysfunction due to constant traction upon the conus medullaris. ${ }^{3}$

Multiple aetiological factors have been described which are associated with the development of neural tube defects like, genetic factors, dietary deficiencies, socioeconomic, environmental, and maternal factors ${ }^{13,15}$. Open spinal dysraphism accounts for up to $95 \%$ of all neural tube defects while occult spinal dysraphism accounts for the remaining $5 \%$ of the lesions. Low antenatal obstetric coverage of childbearing women in our society and very few clinical manifestations at birth has delayed the diagnosis of occult spinal dysraphism. ${ }^{4,5,6}$

Occult spinal dysraphism lesions have been further described into different varieties which include meningocele, lipomyelomeningocele, diplomyelia or diastematomyelia, thickening of filum terminale, post-operative intradural adhesions, and adherence of the placode following myelomeningocele repair. ${ }^{7}$ All the above mention varieties of the lesions require open untethering of the cord to improve neurologic manifestations or stop its progression. ${ }^{8,9}$

Over the three decades, much advancement has been achieved regarding the prevention, earlier diagnosis, and treatment of this disorder, to stop the progression of neurologic deterioration. Antenatal dietary supplementation with folic acid has reduced the incidence globally, frequent clinical visits to the obstetric clinics and increasing expertise in antenatal ultrasound, availability of high-frequency ultrasound, antenatal and early post-natal MRI, dynamic or phase-contrast MRI has helped in earlier diagnosis, and improvement in microneurosurgical techniques has led to improved outcome for these patients. ${ }^{10-14}$

However, the rarity of this clinical condition warrants repeats clinical research to improve upon the already achieved developments and as a reminder for the neurosurgical and spine surgical community to remain vigilant regarding the earliest possible diagnosis and good surgical management. In a developing country like Pakistan, the high prevalence of these disorders, low availability of obstetric, advanced diagnostic, and tertiary care neurosurgical facilities, and decreased awareness among the primary health care physicians warrants widely available current research about this entity of disorders. ${ }^{4,5,15}$

Our main focus in this study is to know about surgical outcomes of tethered cord syndrome present to our department Hayatabad medical complex Peshawar in mention duration. Which will be helpful to prevent disability.

\section{MATERIALS \& METHODS}

This was a retrospective study which was conducted at the department of neurosurgery Hayatabad medical complex Peshawar from $1^{\text {st }}$ January 2013 to $31^{\text {st }}$ December 2018. The data of the patients was included as anonymous and used with the permission of the administration.

\section{Inclusion Criteria}

We included a total of 110 patients both male and female patients from the age range 0 to 18 years of children diagnosed case of tethered cord syndrome due to spinal dysraphism in the mentioned period of duration. The institute ethical committee for research evaluation was obtained for approval of the proposed study.

\section{Exclusion Criteria}

Spina bifida cystica and previously operated patients were excluded from the study. 


\section{Data Collection}

The data was collected on a predesigned proforma. All cases who presented to the outpatient department were diagnosed using clinical methods and diagnostic imaging studies such as MRI \& CT scans of the spine were performed. Data was collected about the demographics, clinical symptoms, duration of symptoms, and developmental history.

\section{Clinical Management}

Clinical examination was recorded for back swelling, dermal stigmata, scars, lower limb neurological function, sensory deficits, reflexes. Also, look for any deformities like kyphoscoliosis or limb deformities and the presence/absence of neuropathic ulcers.

Imaging studies were recorded for diagnosis, the level of spinal tethering, presence/absence of syrinx, and spine deformities. During the surgical operation, the diagnosis of the lesion was confirmed and the interventional procedure was recorded. The data was entered and analyzed using SPSS version 20.0 and is presented using charts, tables, and graphs.

\section{Follow-up}

After surgery, the patients were followed up to the date of discharge. During the postoperative course, the development of complications, any additional procedures performed for complication management, and the total length of stay were recorded.

\section{RESULTS}

We have analyzed a total of 110 patients having tethered cord syndrome and got the following results.

\section{Age and Gender Distribution}

The mean age of patients was 9.3 years (SD \pm 4.3). One hundred ten patients with 57 (52.2\%) females and 53 (47.8\%) males were included over the five years.

\section{Clinical Presentations}

The most common presenting complaints were lower limbs pain (60.9\%), backache (34.8\%), symptoms of urinary tract dysfunction (incontinence, retention, difficulty voiding) (30.4\%), and weakness of the lower limbs with gait problems (26.1\%). A majority of patients also complained of the presence of back swelling which was present since birth as shown in Table 1.

Table 1: Clinical Symptoms.

\begin{tabular}{lcc} 
Variables & Frequency & Percentage (\%) \\
Lower limbs pain & 67 & $60.9 \%$ \\
Backache & 38 & $34.8 \%$ \\
Urinary symptoms & 33 & $30.4 \%$ \\
Weakness Lower limbs & 29 & $26.1 \%$ \\
\& gait problems & & \\
\hline
\end{tabular}

\section{Physical Findings}

On clinical examination the findings included back swelling (65.2\%), wasting of the lower limbs (30.4\%), ulceration of the feet $(21.7 \%)$, faun's hairy tail $(21.7 \%)$, skin dimpling over the lumbosacral area, or the swelling (13\%) as shown in Figure (1) and decreased power grade of the lower limbs in these patients. Kyphoscoliosis was present in only two (8.7\%) patients. The clinical diagnoses included lipomyelomeningocele (LMMC) (34.8\%), diplomyelia (21.7\%), meningocele (21.7\%), filum terminale thickening (4.3\%), and congenital dermal sinus (8.7\%) as given in Table 2 and represent in Figure 2. 
Table 2: Physical Findings.

\begin{tabular}{lrr} 
Variables & Frequency & Percentage \\
Lower Limbs Power & & \\
0 & 4 & $4.3 \%$ \\
1 & 4 & $4.3 \%$ \\
4 & 24 & $21.7 \%$ \\
5 & 76 & $69.6 \%$ \\
Feet ulcers & 24 & $21.7 \%$ \\
Wasting & 33 & $30.4 \%$ \\
Faun's tail & 24 & $21.7 \%$ \\
Skin Dimpling & 14 & $13.0 \%$ \\
Swelling & 72 & $65.2 \%$ \\
Kyphoscoliosis & 9 & $8.7 \%$ \\
Dermal Sinus & 9 & $8.7 \%$ \\
Diplomyelia & 24 & $21.7 \%$ \\
Filum Terminale fibrosis & 5 & $4.3 \%$ \\
Lipomyelomeningocele & 38 & $34.8 \%$ \\
\hline
\end{tabular}

\section{Dermal Signs}

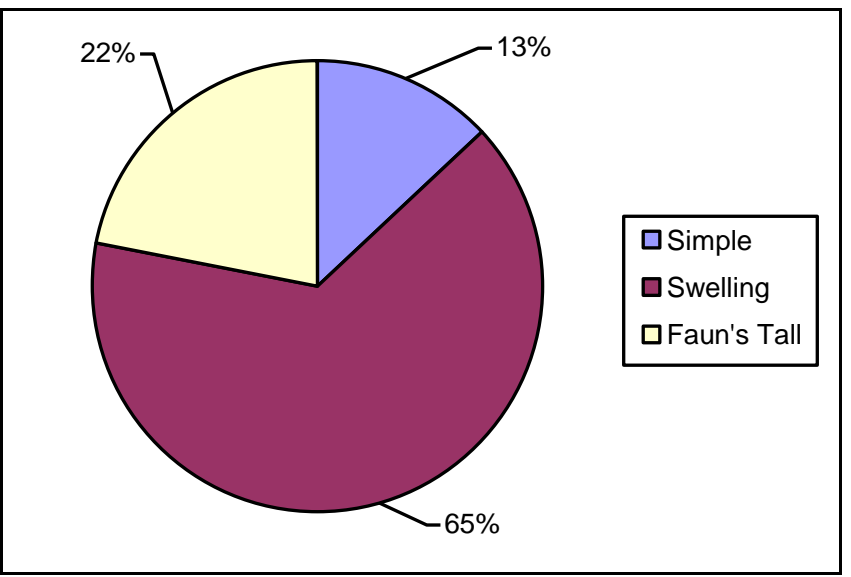

Figure 1: Dermal Signs.

\section{Postoperative Complication}

\section{Postoperative complications}

included cerebrospinal fluid (CSF) leak in 13 (12\%) patients and infection of the wound in (5.5\%) patients. Only two patients underwent reoperation for Dural closure and two patients were treated for CSF leak through the insertion of a lumbar drain. The mean length of stay for the patients was found to be 5.7 days ( $S D \pm 3.0$ ).

\section{Diagnoses}

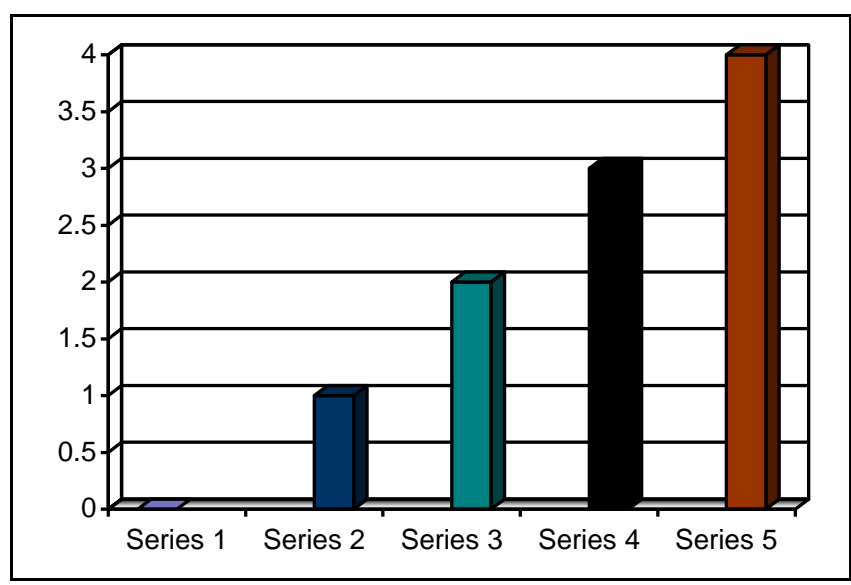

Figure 2: Diagnosis.

Table 3: Postoperative Complications.

\begin{tabular}{lcc} 
Complication & Frequency & Percentage \\
CSF leak & 29 & $26.1 \%$ \\
Wound Infection & 14 & $13.0 \%$ \\
Additional Procedures & - & - \\
Lumbar Drainage & 9 & $8.7 \%$ \\
Reoperation/dura repair & 9 & $8.7 \%$ \\
\hline
\end{tabular}

\section{DISCUSSION}

Spina bifida occulta is a rare entity in the spectrum of neural tube malformation which may accompany tethering of the spinal cord causing a myriad array of symptoms and signs. The tethering produces symptoms by various mechanisms, among which ischemic insults to the spinal cord and nerve roots are one of the most favored explanations. The incidence of tethered cord syndrome is reported to be in the range of 0.05 to 0.25 per 1000 births. $^{16}$ The clinical features of occult spinal dysraphism and associated tethered cord syndrome are insidious and in some instances, they may be absent until the neurological sequelae become apparent. The symptoms of the tethered cord syndrome may sometimes appear later in adolescence or adult life and it has been shown that untethering by surgery has very satisfactory results in terms of neurological improvement. ${ }^{16-18}$ The insidious 
nature of the tethering of the spinal cord warrants a heightened clinical vigilance for both the general physicians as well as specialists. ${ }^{2}$ Iskandar et al have shown the obvious advantage of surgical intervention for tethered cord syndrome in terms of neurological and functional improvements, despite the wide debate about the feasibility of the intervention in adolescence and adult patients. ${ }^{19}$ Therefore, it is apparent that surgical intervention especially in the presence of symptomatic tethered cord syndrome has clear benefits over the wait and watch approach. ${ }^{2,20}$

The spectrum of spina bifida occulta varies in frequency concerning the individual lesions, however, diplomyelia and lipomyelomeningocele collectively form about $60 \%$ of the total. ${ }^{16,20}$ Quite similar are the findings in our study where more than $56 \%$ of patients comprised of Lipomyelomeningocele (34.8\%) and diplomyelia (21.7\%). The majority of pediatric patients present within an age range of 7 to 12 years (mean 9 years in our study) with complaints of pain occurring in legs, hips, or back $(95.7 \%$ collectively in our study) followed by dysfunction of the bowel or bladder (30.4\%), various degrees of motor deficits, neuropathic ulceration of the feet, orthopedic deformities and dermal stigmata in the form of hair tuft over the lumbosacral area, dimples and swelling caused by the underlying lipomata. These findings have been noted in the studies by Das et al, Sarris et al, Muthukumar et al, Solmaz et al., Koo et al., Phi et al. and Iskandar et al. ${ }^{2,711,12}$ Findings ofthe present study concur with the findings of the above studies. These consistencies in the findings of various studies denote that the presenting symptoms of Spina bifida occulta and Tethered cord syndrome are widely constant, despite differences in patterns of appearance, and can be relied upon in a clinical perspective.

Magnetic Resonance Imaging is the diagnostic tool of choice for defining the specific lesion of Spina bifida occulta and the level of tethering of the spinal cord. 2,16,22 Das et al, have also described the efficacy of ultrasonography for defining Spina bifida occulta in very young neonates. However, for older patients, MRI has superseded CT scan as it delineates the soft tissue pathology clearly and defines the tethering level. ${ }^{2}$ In addition to defining the spinal dysraphism, MRI was used by Erfani et al and Gharedaghi et al, for evaluating the presence or absence of syrinx and its resolution after surgery and also for the determination of congenital spinal orthopedic deformities such as congenital scoliosis. ${ }^{23,24}$ MRI was the principal investigation after clinical diagnosis in our study. However, we tried to further confirm the lesion during surgery along with its spinal level which was shown by MRI during preoperative workup. This strategy helped us additionally in confidently classifying the lesion according to their type as found on open surgery.

Open surgical release of the tethered cord is the standard method of intervention in symptomatic cases of Tethered cord syndrome due to Spina bifida occulta. There has been increasing use of release and repair of Tethered cord syndrome under magnification and with the use of motor and sensory evoked potentials. ${ }^{16,22}$ It has also been shown that these two modalities help improve the postoperative results in terms of functional improvement and complications avoidance. Four principle surgical methods are recommended by a review by Das et al. ${ }^{2}$ namely: laminectomy \& detethering, lipoma excision, resection of a bony spur, and division of filum terminale.

We used resection of the lipoma/spur and release of the Dural sac from any adhesions as well as a repair under magnification. Motor or sensory evoked potentials were not used. A very limited untethering approach was used for those who had minimal or no motor deficits and only the Dural sac was released taking care of the nerve rootlets.

The postoperative course of these patients usually is a dramatic improvement in the symptoms of pain with only a minority of patients 
experiencing a transient worsening of sensory or motor deficits. We, however, followed the patients for the occurrence of early postoperative complications. The two major postoperative complications which affect the early postop course were CSF leak (26.1\%) and wound infection (13\%) mention in Table 4. No patient experienced a worsening or appearance of new motor deficit in our study, although it has been reported in $3.9 \%$ to $5 \%$ of patients of untethering surgery. ${ }^{22}$

Wound infections responded quickly by instituting barrier dressing methods and the use of intravenous antibiotics according to the sensitivity patterns. The mean hospital length of stay was found to be 5.7 days. Only two (8.7\%) instances of reoperation for the repair of the dural defect in cases of CSF leak were found and two (8.7\%) cases of CSF leak were relieved with insertion of a lumbar drain above the region of the dura repair. Most of the CSF leaks occurred in patients who had a meningocele sac repaired at operation. This signifies the fact that the dura in this subset of patients is very thin and closing sutures usually hold poorly. A meticulous closure technique is therefore advised. Studies by Solmaz et al and Galhom et al, employed similar techniques of untethering and repair of the thecal sac with complications of CSF leak and wound infections (20\% CSF leak and $10 \%$ wound infection rates) similar to our study. The mean hospital stay was similar to the above studies as well as a study by Shweikeh et al, where the mean hospital stay was 3.5 to 5.1 days. $^{25}$

\section{CONCLUSION}

Early diagnosis and optimal treatment strategy development is the key to a successful outcome in patients with Tethered cord syndrome due to Spina bifida occulta. Earlier diagnosis is only possible if a high degree of clinical suspicion is observed, especially by the primary care physicians and neurosurgeons. Further studies are required to further elucidate the association of various clinical correlates with occult spinal dysraphism and tethered cord syndrome and to establish their diagnostic and prognostic role.

\section{RECOMMENDATIONS}

Early diagnosis of tethered cord syndrome has a better prognosis. So general public and general practitioners should know about these conditions and their signs/ symptoms. Proper surgical steps to detethering ofthe spinal cord are essential in spina bifida to prevent future neurological complications.

\section{REFERENCES}

1. Hoffman HJ, Hendrick EB, Humphreys RP. The tethered spinal cord: its protean manifestations, diagnosis, and surgical correction. Childs Brain, 1976; 2 (3): 145-55.

2. Das K, Shubha AM. The management of tethered cord syndrome complicating occult spinal dysraphism in children: Experience from a spina bifida clinic. JIMSA. 2014; 27 (2): 86-90.

3. Hendrick EB, Hoffman $H$, Humphreys RP. The tethered spinal cord. Clin Neurosurg. 1983; 30: 457-63.

4. $Y i \quad Y$, Lindemann $M$, Colligs $A$, Snowball $C$. Economic burden of neural tube defects and impact of prevention with folic acid: a literature review. Eur J Pediatr. 2011; 170: 1391-1400.

5. Lo A, Polsek D, Sidhu S. Estimating the burden of neural tube defects in low- and middle-income countries. J Glob Health, 2014; 4 (1): 010402.

6. Mosley BS, Cleves MA, Siega-Riz AM, Shaw GM, Canfield MA, Waller DK, et al. Neural tube defects and maternal folate intake among pregnancies conceived after folic acid fortification in the United States. Am J Epidemiol. 2009; 169: 9-17.

7. Sarris $\mathrm{CE}$, Tomei $\mathrm{KL}$, Carmel $\mathrm{PW}$, Gandhi $\mathrm{CD}$. Lipomyelomeningocele: pathology, treatment, and outcomes. A review. Neurosurg Focus. Oct. 2012; 33 (4): E3.

8. Mishra SS, Panigrahi S, Dhir MK, Parida DK. Tethered cord syndrome in adolescents: Report of two cases and review of literature. J 
Pediatr Neurosci. 2013; 8 (1): 55-8.

9. Jeelani Nu O, Jaspan T, Punt JAG. Tethered cord syndrome after myelomeningocele Repair, 1999; 318: 516-17.

10. Samuels R, McGirt MJ, Attenello FJ, Ambrossi GLG, Singh Neil, Solakoglu Can, et al. Incidence of symptomatic retethering after surgical management of pediatric tethered cord syndrome with or without duraplasty. Childs Nerv Syst. 2009; 25: $1085-89$.

11. Muthukumar N. Congenital spinal lipomatous malformations: part I - Classification. Acta Neurochir (Wien), 2009; 151 (3): 179-88:197.

12. Muthukumar N. Congenital spinal lipomatous malformations: part II - Clinical presentation, operative findings, and outcome. Acta Neurochir (Wien), 2009 Mar; 151 (3): 189-97; Discussion 197.

13. Golalipour MJ, Qorbani M, Mirfazeli A, Mobasheri E. Risk factors of neural tube defects in Northern Iran. Iran Red Crescent Med J. 2014; 16 (6): e7940.

14. Grewal J, Carmichael SL, Song J, Shaw GM. Neural tube defects: An analysis of neighbourhood-and individual-level socio-economic characteristics. Paediatr Perinat Epidemiol. 2009; 23 (2): 116-24.

15. Au KS, Koch AA, Northrup H. Epidemiologic and genetic aspects of spina bifida and other neural tube defects. Dev Disabil Res Rev. 2010; 16 (1): 515.

16. Solmaz I, Izci Y, Albayrak B, Centinalp E, Kural C, Sengul $G$, et al. Tethered cord syndrome in childhood: Special emphasis on the surgical technique and review of the literature with our experience. Turk Neurosurg. 2011; 21 (4): 516-21.

17. Koo IK, Kim SH, Bae JH, Kim OL, Choi BY, Cho SH. Tethered cord syndrome in adulthood. J Korean Neurosurg Soc. 1997; 26: 830-35.
18. Phi JH, Lee DY, Jahng TA, Chung CK, Kim HJ. Tethered cord syndrome in adulthood: Reconsidering the prognosis. J Korean Neurosurg. Soc. 2004; 36: 114-19.

19. Iskandar BJ, Fulmer BB, Hadley MN, Oakes WJ. Congenital tethered spinal cord syndrome in adults. Neurosurg Focus, 2001; 10 (1): e7.

20. Kang JK, Yoon KJ, Ha SS, Lee IW, Jeun SS, Kang SG. Surgical management and outcome of tethered cord syndrome in school-aged children, adolescents and young adults. J Korean Neurosurg Soc. 2009; 46: 468-71.

21. Kang JK, Lee KS, Jeun SS, Kang SG, Yoon KJ, Ha SS. Tethered cord syndrome; Surgical indication, technique and outcome. J Korean Neurosurg Soc. 2007; 42: 77-82.

22. Galhom AE, Deeb WA, Osama A. Early clinical characteristics and surgical outcome in 10 children with occult spinal dysraphism. Egypt J Neurol Psychiat Neurosurg. 2013; 50 (2): 127-34.

23. Erfani MA, Ganjavian MS, Ameri E, Namazi $H$, Solooki S. Occult intraspinal abnormalities and congenital scoliosis. JRMS. 2007; 12 (2): 53-57.

24. Gharedaghi $M$, Samini $F$, Mashhadinejad $H$, Khanjavi M, Samini M. Orthopedic lesions in tethered cord syndrome: The importance of early diagnosis and treatment on patient outcome. Arch Bone Joint Surg. 2014; 2 (2): 93-97.

25. Shweikeh F, Al-Khouja L, Nuño $M$, Johnson JP, Drazin $D$, Adamo MA. Disparities in clinical and economic outcomes in children and adolescents following surgery for tethered cord syndrome in the United States. J Neurosurg Pediatr. 2015: 1-7.

\section{Additional Information}

Disclosures: Authors report no conflict of interest.

Ethical Review Board Approval: The study was conformed to the ethical requirements.

Human Subjects: This was the retrospective study. The data of the patients was included as anonymous and used with the permission of the administration.

\section{Conflicts of Interest:}

In compliance with the ICMJE uniform disclosure form, all authors declare the following:

Financial Relationships: All authors have declared that they have no financial relationships at present or within the previous three years with any organizations that might have an interest in the submitted work.

Other Relationships: All authors have declared that there are no other relationships or activities that could appear to have influenced the submitted work. 


\section{AUTHORS CONTRIBUTIONS}

\begin{tabular}{|l|l|l|}
\hline Sr.\# & Author's Full Name & Intellectual Contribution to Paper in Terms of: \\
\hline 1. & Ayaz Ahmad & Study design and methodology. \\
\hline 2. & Muhammad Ali Noman & Paper writing and data calculations. \\
\hline 3. & Muhammad Mukhtar & Data collection and calculations. \\
\hline 4. & Imran Khan, Muhammad Mushtaq & Analysis of data and interpretation of results etc. \\
\hline 5. & Shahid Ayub & Literature review and referencing. \\
\hline
\end{tabular}

